\title{
Article
}

\section{Development and initial validation of a measure of metacognitive beliefs in health anxiety: The MCQ-HA}

Bailey, Robin and Wells, Adrian

Available at http://clok.uclan.ac.uk/13567/

Bailey, Robin and Wells, Adrian (2015) Development and initial validation of a measure of metacognitive beliefs in health anxiety: The MCQ-HA. Psychiatry Research, 230 (3). pp. 871-877. ISSN 0165-1781

It is advisable to refer to the publisher's version if you intend to cite from the work. http://dx.doi.org/10.1016/j.psychres.2015.11.035

For more information about UCLan's research in this area go to http://www.uclan.ac.uk/researchgroups/ and search for <name of research Group>.

For information about Research generally at UCLan please go to http://www.uclan.ac.uk/research/

All outputs in CLoK are protected by Intellectual Property Rights law, including Copyright law. Copyright, IPR and Moral Rights for the works on this site are retained by the individual authors and/or other copyright owners. Terms and conditions for use of this material are defined in the policies page.

\section{CLoK}

Central Lancashire online Knowledge www.clok.uclan.ac.uk

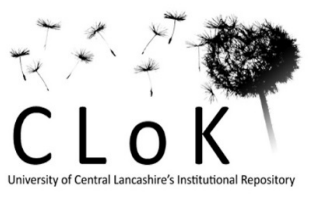




\section{Development and Initial Validation of a Measure of Metacognitive Beliefs in Health Anxiety: The MCQ-HA.}

\section{Introduction}

Health anxiety (HA) is prevalent in both community samples (3.5\%) (Sunderland, Newby \& Andrews, 2013) and in medical care services (20\%) (Tyrer et al., 2011). Disorders of HA exist on a continuum from mild to severe (Ferguson, 2009; Taylor \& Asmundson, 2004) and have a major functional impact on the sufferer and health care services (Barsky, Ettner, Horsky \& Bates, 2001; Fink, Ørnbøl, \& Christensen, 2010).

Cognitive-behavioural models have been used to conceptualise and treat health anxiety. It is a condition normally associated with beliefs regarding the presence of illness and a preoccupation about being ill (Salkovskis, Rimes, Warwick \& Clark, 2002). These approaches specify several dysfunctional cognitions as important in both the development and maintenance of the disorder (Abramowitz \& Braddock, 2008; Fergus, 2013; Marcus \& Church, 2003). CBT treatments tend to target specific beliefs (e.g. "Unexplained symptoms are a sign of serious illness") as a means of reducing health anxiety symptoms and such approaches have demonstrated efficacy (see Olatunji et al., 2014 for a review).

More recently, Wells and Matthews $(1994 ; 1996)$ have suggested that the beliefs emphasised in cognitive-behavioural theories may not be so central to psychological disorder after all. Instead, they propose that the regulation of thinking and beliefs about thoughts are more important. In their Self-Regulatory Executive Function model (S-REF), psychological 
disorders such as health anxiety result from excessive thinking (e.g. about illness) that is difficult to bring under control. This thinking style is dominated by worry and rumination and is the consequence of metacognitive beliefs.

Metacognition is a far reaching term that incorporates knowledge and regulation of various aspects of cognitive activity (Moses \& Baird, 1999). The Wells \& Matthews (1994; 1996) model is supported by data demonstrating that metacognitive knowledge in the form of specific beliefs individuals hold about their own cognition is reliably correlated with emotional disorder and symptoms, such as OCD (e.g. Gwilliam, Wells, \& Cartwright-Hatton, 2004), generalised anxiety (e.g. Khawaja \& McMahon, 2011; Wells \& Carter, 1999; 2001), PTSD (Bennet \& Wells, 2010) and depression (e.g. Papageorgiou \& Wells, 2009). Studies that have tested the role of metacognition in psychological disorders have used the Metacognitions Questionnaire (MCQ: Cartwright-Hatton \& Wells, 1997) or the shortened version MCQ-30 (Wells \& Cartwright-Hatton, 2004). This measure captures 5 different dimensions of metacognition on the following subscales; 1) positive beliefs about worry, (2) negative beliefs about thoughts concerning uncontrollability and danger, (3) cognitive confidence (4) negative beliefs concerning the consequences of not controlling thoughts, and (5) cognitive self-consciousness.

In the domain of health anxiety a number of studies have used the MCQ to explore the relationship between metacognition and this disorder. Bouman and Meijer (1999) identified that the MCQ subscale of cognitive self-consciousness was a positive predictor of extreme health anxiety, hypochondriasis. Barenbrügge, Glöckner-Rist, and Rist (2013) identified that both negative and positive metacognitive beliefs were strongly and positively associated with all aspects of health anxiety. Bailey and Wells (2013) also identified that metacognitive beliefs were strongly associated with health anxiety and had predictive power over and above 
other correlates associated with this disorder, such as illness cognition and somatosensory amplification. In an experimental study Kaur, Butow and Thewes (2011) found that metacognitions were strongly and positively associated with an attentional bias to health related information.

Although the MCQ is the gold standard measure of metacognitive beliefs it does not directly capture health-anxiety specific metacognitive beliefs and therefore may have reduced sensitivity and specificity in this context. To facilitate research on the Wells \& Matthews model applied to health anxiety the present study reports on the development and initial evaluation of a new metacognitive measure of health anxiety, the Metacognitions Questionnaire-Health Anxiety (MCQ-HA). When developing and evaluating a new measure Matsunaga (2010) reinforces Thomson's (2004) recommendations of a three stage approach, which was used to guide the present study; (1) Screening items using principal components analysis; (2) Scrutinising the remaining items using exploratory factor analysis; \& (3) detailed examination of the factor structure using confirmatory factor analysis. We also report preliminary data on the internal consistency and convergent and divergent validity of the measure.

\section{Study 1}

\section{Methods}

Participants: Three hundred and fifty one student nurses completed the questionnaire. This particular student demographic was chosen as previous research has revealed that health anxiety is normally distributed in student populations (Marcus, Hughes \& Arnau, 2008) and in nursing students specifically (Zhang et al., 2014). Information about participant's age and gender was obtained. Three hundred and fourteen of these participants 
were female ( $89.5 \%$ of the sample) and thirty seven were male (10.5\% of the sample). All participants provided details about their age. The age range was 19-59 years, with a mean age of 27 years $(\mathrm{SD}=7.48$ years $)$.

Measures. The Meta-Cognitions about Health Questionnaire (MCQ-HA):

Two sources of information were used to generate initial categories of items for the new MCQ-HA; 1) the items and subscales on the existing MCQ-30; 2) patient reports of metacognitions recorded by the second author during treatment of health anxiety cases. On this basis the following categories of items were generated: 1) Negative beliefs about optimistic thinking (e.g. "I will be punished for thinking I am in good health"); 2) Positive beliefs about worry (e.g. “Anticipating illness means I won’t be taken by surprise”); 3) Beliefs about uncontrollability of worry (e.g. "Only if I have a diagnosis will I be able to stop worrying"; 4) Beliefs about the danger of worrying (e.g. "I could lose my mind through health worry"; and 5) Fusion beliefs (e.g. "Thinking I am ill means I am ill”). Twenty items were initially generated to capture these domains.

Worthington and Whittaker (2006) recommend that item quality should be subjected to expert review, as the second author is a leading expert on metacognition and developer of the MCQ, we relied on this and the source of items to enhance content validity. We retained the 1- 4 response scale and labels used in the MCQ-30: 1 (Do not agree); 2 (Slightly agree); 3 (Agree moderately), and 4 (Agree very much).

To assess item unidimensionality inter-item correlations were inspected and appeared in the main to be moderate but not too high (.30-.60) which indicated the items were measuring a similar but not singular construct. 


\section{Overview of Data Analysis.}

To investigate the initial pool of items generated and prepare for exploratory factor analysis principle components analysis (PCA) was conducted on the initial 20 item measure. Using SPSS version 21 the default principal components method of factor extraction was performed on the data, as it has been shown as an acceptable data reduction technique (Costello \& Osbourne, 2005). Eigenvalues above 1 was selected as this is considered appropriate when running a primary analysis of data screening (Field, 2013; Matsunaga, 2010). As there was a potential for the items in this measure to be correlated, as has been shown in other metacognitive measures, i.e. the MCQ (Cartwright Hatton \& Wells, 1997), oblique rotation (promax) was used. Oblique rotation has been shown to generate solutions with correlated components (Costello \& Osbourne, 2005; Henson \& Roberts, 2006). Both the structure matrix and pattern matrix were inspected and items screened to identify the strength of loadings on the generated components. When screening the items on the pattern matrix, those that had a primary factor loading lower than .32 (Tabachnick \& Fidell, 2007) and/or a cross loading above .30 (Comery \& Lee, 1992) were deemed problematic.

\section{Results}

Three components emerged and of the 20 items five did not meet criteria and were not retained: 1) "I could lose my mind through health worry"; 2) "Worrying about health will make me more vulnerable to illness"; 3) "Thinking I am ill means I am ill”; 4) "Being 
optimistic about my health will help me detect problems before it is too late"; and 5) “Anticipating illness means I won't be taken by surprise”. One item on component three "Worrying about my health will help me detect problems before it is too late" was also removed as it could not be interpreted in a meaningful way in relation to the other items.

The remaining 14 items were analysed further using a principal components method, with the default factor extraction method "Eigenvalues above 1 retained" and rotated using the oblique method (promax). All items had primary loadings above .32 and no cross loadings above .30 and were therefore retained (Table 1).

\section{Study 2}

PCA is an extraction method utilised to reduce the number of items, exploratory factor analysis (EFA) aims to identify latent variables that make up the shared variance amongst these items (Worthington \& Whitaker, 2006). The specific goal of EFA is to determine the number of underlying factors, identifying which items load on which factors and identifying those that do not load sufficiently (Thompson, 2004). For these purposes FA is considered superior to PCA (Snook \& Gorsuch, 1989; Widaman, 1993) and a more useful approach when constructing new measures and more generalizable to confirmatory factor analysis (for a review see Worthington \& Whitaker, 2006).

\section{Method}

\section{Participants}

Five hundred and fifty three students completed the questionnaire. Information about gender was obtained from all participants. Four hundred and fifty of these participants were 
female ( $82 \%$ of the sample) and one hundred and three were male (18\% of the sample). All participants provided details about their age. The age range was 19-56 years, with a mean age of 28 years $(\mathrm{SD}=7.32$ years $)$.

\section{Results:}

(i) Principal axis factoring method of factor extraction was performed on the 14 items, this method is considered more appropriate for exploratory factor analysis as it is better at defining the latent variables underlying the data (Fabrigar, Wegener, MacCallum \& Strahan, 1999). Oblique rotation was employed with the method set again to "promax".

The Kaiser-Meyer-Olkin (KMO) measure of sampling adequacy was .91 which is considered superb (Hutcheson \& Sofroniou, 1999), and Bartlett's test of sphericity X2 = 3015.989 was highly significant $\mathrm{p}<.0001$, both indicating factor analysis was appropriate.

After visually inspecting the scree plot there appeared to be three factors at the point of inflection. Although the scree plot is one of the most popular methods of determining factor retention, it has been considered not always the most reliable (Costello \& Osborne, 2005). An alternative factor extraction method, Horn's (1965) parallel analysis, has been shown to be one of best ways to determine the correct number of underlying factors (Zwick \& Velicer, 1986; Henson \& Roberts, 2006; Patil, Singh, Mishra, \& Donovan, 2008), and computes whether eigenvalues observed from the real data are larger than the corresponding average eigenvalues from random data. Using O’Connor's (2000) syntax script applied to SPSS and set for "principal axis factoring", the first three factor eigenvalues exceeded the $95^{\text {th }}$ percentile criteria for random data eigenvalues and explained $59 \%$ of the variance. The 
first factor was well above the chance level (actual eigenvalue $=5.22$; estimated average eigenvalue $=.299 ; 95$ th percentile eigenvalue $=.354)$; as was the second factor $($ actual $=$ 1.00 ; estimated $=.236 ; 95^{\text {th }}$ percentile eigenvalue $\left.=.294\right)$ and the third (actual $=.499$; estimated $=.185 ; 95^{\text {th }}$ percentile eigenvalue $=.224$ ). Actual eigenvalues for factor four (actual $=.132$; estimated $=.142 ; 95^{\text {th }}$ percentile eigenvalue $\left.=.171\right)$ and factors beyond were not larger and therefore did not meet this criterion.

Of the three factors extracted five items loaded highly on factor 1 and 2, and four items on factor 3, with none loading lower than .32 (Tabachnick \& Fidell, 2007) and the solution was interpretable (Table 2). Factor 1 contained metacognitive beliefs relating to beliefs about the usefulness of biased thinking (negative is helpful and positive is unhelpful) and was labelled "Beliefs about biased thinking". Factor 2 contained metacognitive beliefs relating to negative thinking causing illness, and was labelled "Beliefs that thoughts can cause illness". Factor 3 contained items relating to metacognitive beliefs about the uncontrollability of thinking about illness and was labelled "Beliefs that thoughts are uncontrollable").

(ii) To support the validity of the scale a confirmatory factor analysis (CFA) using Amos 20.0 was performed on the 14-item three factor solution to assess model fit. As a result all standardised regression weights were above the acceptable cut off of 0.5 (Hair, Black, Babin, Anderson, \& Tatham, 2006), range 0.58-0.8. A lower Chi Square value indicates a better fit, however, the $\boldsymbol{X}^{2}$ value in this study was 198 with 73 degrees of freedom and was significant .001. For models with more than 200 cases (in our case 550), the chi square is almost always statistically significant (Schumacker \& Lomax, 1996). For these reasons 
alternative fit indices were used to assess model fit. Goodness of fit index (GFI) was examined and was .951 meeting the cut off criteria of .95 established by Miles and Shevlin (1998). Root mean squared error of approximation (RMSEA) was .056 suggesting a good fit based on Hu and Bentler's $(1998 ; 1999), \leq .06$ cut-off criteria. The standardized root mean square residual (SRMR) was .381 which again is lower than .5 a threshold deemed to be indicative of a well-fitting model (Diamantopoulos \& Siguaw, 2000). To assess incremental fit, i.e. the improvement of fit for our tested model compared with a more restricted baseline model, the Comparative Fit Index (CFI) was examined (.958) and exceeded the recommended $\geq 0.95$ suggested by $\mathrm{Hu}$ and Bentler, (1999) as a good fit.

\section{Study 3}

\section{Method}

To assess the internal consistency of the factors (subscales), their convergent, divergent and incremental validity (against existing measures), the 14 item questionnaire and accompanying measures were distributed to a new sample.

Participants. Two hundred and fifty nine nursing students completed the questionnaire. Information about gender was obtained from all participants. Two hundred and thirty five of these participants were female (91\% of the sample) and twenty four were male (9\% of the sample). All participants provided details about their age. The age range was 1950 years, with a mean age of 26 years $(\mathrm{SD}=6.9$ years $)$.

Measures: The Whiteley Index: (WI; Pilowsky 1967) 
The Whiteley index is one of the most widely utilised measures of hypochondriasis and health anxiety. The measure consists of fourteen items with the original version using a binary yes/no format. Other versions of the measure and the one used in this study use a fivepoint Likert scale $(1=$ not at all to $5=$ extremely) to measure the severity of hypochondriasis / health anxiety, (Barsky, Wyshak, \& Klerman, 1986). The measure has shown good internal consistency in medical outpatients $\alpha=.80$, general practice $\alpha=.78$ and general population $\alpha$ $=.76$ (Speckens et al., 1996). It has also demonstrated good to excellent reliability and validity (Greeven et al., 2007; Fink et al., 1999; Stewart \& Watt, 2001;; Speckens, 2001).

Cognition about Body and Health Questionnaire: (CABAH: Rief, Hiller, \& Margraf, 1998)

The CABAH is a self-report measure that captures cognitions, attitudes and behaviours associated with cognitive behavioural theories of health anxiety (Rief et al., 1998; Weck, Bleichhardt \& Hiller, 2010; Hiller, Leibbrand, Rief, \& Fichter, 2005). The measure consists of five subscales which measure: catastrophizing interpretation of bodily complaints, autonomic sensations, bodily weakness, intolerance of bodily complaints and health habits. All items are scored on a four point Likert Scale

The overall internal consistency (Cronbach's alpha) of the CABAH is 0.90 , with the five subscales ranging from $\alpha=.67$ to $\alpha=.88$ (Rief et al 1998). The measure has demonstrated good convergent and divergent validity (Leibbrand, Hiller \& Fichter, 2000).

The Metacognitions Questionnaire-30 (MCQ-30; Wells \& Cartwright-Hatton, 2004)

The MCQ-30 is a briefer version of the original MCQ (Cartwright-Hatton \& Wells, 1997) and considered a gold standard measure of metacognitive beliefs. The measure has 30 
items and five specific subscales capturing different aspects of metacognition: cognitive confidence (MCQCC), positive beliefs about worry (MCQPOS), cognitive self-consciousness (MCQCSC), negative beliefs about uncontrollability of thoughts and danger ((MCQNEG) and beliefs about the need to control thoughts (MCQNC) (Wells \& Cartwright Hatton, 2004). The MCQ-30 possesses good internal consistency and convergent validity (e.g., Cook, Salmon, Dunn, \& Fisher, 2014; Myers \& Wells, 2005; Wells \& Cartwright-Hatton, 2004); predictive validity (Spada, Mohiyeddini \& Wells, 2008) and test-retest reliability (Wells \& Cartwright Hatton, 2004).

Neuroticism scale of the Eysenck Personality Questionnaire-Revised: Short Form (EPQ-R-N; Eysenck, Eysenck, \& Barrett, 1985)

EPQ-R is a commonly used self-report measure of personality. It includes 48 items and 4 subscales: extraversion (12 items), neuroticism (12 items), psychoticism (12 items), and lie (12 items). Each question on the subscale is answered in a, 'yes' or 'no' format with items scored 1 or 0 . The Neuroticism subscale covers personality trait characteristics such as emotional instability (Eysenck, 1990) and has been reported to have good internal consistency of $\alpha=.80$ (Female) $\alpha=.84$ (male) (Eysenck et al., 1985).

\section{Results}

\section{Internal consistency}

The internal consistency of the MCQ-HA was examined using corrected item-total correlations for the full-scale which ranged from (0.39-0.71). For the individual subscales these were as follows: "Beliefs about biased thinking" (0.54-0.75), "Beliefs that thoughts can 
cause illness" (0.44-0.60), and "Beliefs that thoughts are uncontrollable" (0.54-0.72). These coefficients show subscale items are correlated with their subscales and are higher than the acceptable standard of .30 (Nunnally \& Bernstein, 1994).

Internal consistency was examined using Cronbach's alpha computed for the total score and the five subscales. Alpha scores ranged from good to excellent: MCQ-HA Total $\alpha$ $=.89$; "Beliefs about biased thinking" $\alpha=.83$; "Beliefs that thoughts can cause illness" $\alpha$ $=.78$; and "Beliefs that thoughts are uncontrollable" $\alpha=.81$.

\section{Convergent \& Divergent Validity}

Supporting the convergent validity of the MCQ-HA, the results showed a significant positive correlation between total score and health anxiety symptoms as measured by the total score on the Whiteley Index and Cognitions about Body \& Health Questionnaire. Equally, the three subscales also demonstrated convergent validity with measures of health anxiety. Overall, the correlations ranged from moderate to high in magnitude, with the strongest subscale correlations found between both measures of health anxiety and "beliefs that thoughts are uncontrollable" (Table 3).

To assess divergent validity correlations were run between the MCQ-HA subscales, the Whitley Index total and The EPQ-R-N. We predicted that the MCQ-HA would have a stronger correlation with the health anxiety measure than with the measure of general anxiety vulnerability i.e. neuroticism. Correlations revealed a strong association between all MCQHA subscales and the Whiteley Index, however significant correlations only existed between the EPQ-R-N, the MCQ-HA total and one MCQ-HA subscale (Table 3). 


\section{Incremental Validity}

An important question concerns the incremental utility (validity) of the MCQ-HA beyond the MCQ-30. We examined if MCQ-HA could explain additional variance in the WI over and above the MCQ-30, thus establishing the potential utility of the new measure in subsequent research in the area of health anxiety. To examine this a hierarchical regression was run in which MCQ-30 subscales were entered as a block on step 1 and then the MCQHA subscales entered on a block on step 2. We were interested in the increment in R square on this second step and the final independent subscales in the equation. The MCQ-30 subscales accounted for $30 \%$ of the variance in health anxiety on step 1 . The MCQ-HA subscales entered at step 2 explained an additional $26 \%$ of the variance in health anxiety. On the final step of the equation four of the subscales made a unique and statistically significant contribution to health anxiety: MCQ-30 -“Uncontrollability and Danger” $(\beta=.18, \mathrm{P}<.005)$; MCQ-HA- "Thoughts about illness are uncontrollable" $(\beta=.44, \mathrm{P}<.001)$; MCQ-HA -"Beliefs about biased thinking” ( $\beta=.14, \mathrm{P}<.05)$ and MCQ-HA-"Beliefs that thoughts can cause illness" $(\beta=.12, \mathrm{P}<.05)$.

\section{Discussion}


The metacognitive model (Wells \& Matthews, 1994; Wells, 2009) implicates metacognitive beliefs about thoughts rather than other belief domains in the development of psychological disorder symptoms. Consistent with the model previous studies have demonstrated that metacognitions predict HA symptoms and explain a greater amount of variance than illness beliefs (Bailey \& Wells, 2013). However, testing the model would be facilitated by developing more specific and sensitive measures of health-anxiety related metacognitions. The purpose of the present study was to develop and psychometrically evaluate a questionnaire measure designed to assess metacognitive beliefs that may be more specific to health anxiety.

PCA was used to identify and screen appropriate items for the measure. This process revealed 14 items which loaded independently and meaningfully across three components. The other six items did not pass the established criteria for retention and were dropped. Subsequent exploratory factor analysis on new data-sets also revealed a three factor solution. The three observed subscales were labelled: (1) Beliefs about biased thinking: this related to beliefs that thinking in certain ways can prevent or cause illness. (2) Beliefs that thoughts can cause illness: this was made up of beliefs that having illness related thoughts can lead to negative health outcomes. (3) Beliefs that thoughts are uncontrollable: this related to beliefs that thinking about illness is uncontrollable. Confirmatory factor analysis supported the structure of the measure with most indices confirming a good fit to a three-factor solution.

Assessment of internal consistency supported the homogeneity of subscales and the full measure. Correlations with measures of health anxiety demonstrated acceptable convergent validity of the scale and subscales. Preliminary evidence of divergent validity was obtained in demonstrating stronger relationships between MCQ-HA and health anxiety than between MCQ-HA and general anxiety proneness assessed with the EPQ-R-N. 
To examine the potential utility of the MCQ-HA incremental validity was examined to determine if the MCQ-HA accounted for additional variance in health anxiety over and above that accounted for by the more generic measure of metacognitions the MCQ-30. Results indicated that the MCQ-HA variables explained an additional $26 \%$ of the variance over and above MCQ-30 subscales. Equally all three MCQ-HA subscales emerged as independent predictors of health anxiety. Overall this would indicate in this sample the MCQHA appears to be a valid and potentially useful predictor of health anxiety.

The present findings support the metacognitive model and confirm that specific metacognitive beliefs are positively associated with health anxiety. Furthermore, there is demonstrable utility in measuring such metacognitions in attempting to statistically explain health anxiety symptoms. The MCQ-HA is likely to prove a useful addition in assessing the role of metacognitions in health anxiety and in continuing to test the relative contributions of different components of cognition.

However, there are limitations with this present study that future studies should aim to overcome. As participants in the current study were a specific non-health seeking sample, more diverse samples and including clinical samples would need to be used to establish the generalizability of the factor structure and reliability of the measure. However, as noted health anxiety is normally distributed in student groups generally (Marcus et al, 2008) and medical based students specifically (Azuri, Ackshota, \& Vinker, 2010; Zhang et al, 2014). We have not established the stability of MCQ-HA subscale scores over time and therefore at present we do not have data on the re-test reliability of the scales.

The demographic was predominantly young, white and female and as a result limits the generalizability of the correlation analyses. In particular, as the samples predominantly 
consisted of females the latent structure of items in males needs to be determined and wider generalizability of the results is unknown.

In conclusion, the preliminary findings from this study support the assessment of health-anxiety specific metacognitions and provide justification for future research work evaluating and using the MCQ-HA. Development of this tool provides a means of testing metacognitive models against cognitive accounts of health anxiety and may subsequently support important conceptual and therapeutic developments in this area.

\section{References}

Abramowitz, J. S., \& Braddock, A. E. (2008). Psychological treatment of health anxiety and hypochondriasis: A biopsychosocial approach. Washington: Hogrefe.

Azuri, J., Ackshota, N., \& Vinker, S. (2010). Reassuring the medical students' disease- Health related anxiety among medical students. Medical Teacher, 32(7), 270- 275.

Bailey, R., \& Wells, A. (2013). Does Metacognition Make a Unique Contribution to Health Anxiety When Controlling for Neuroticism, Illness Cognition, and Somatosensory Amplification? Journal of Cognitive Psychotherapy, 27(4), 327-337. 
Barenbrügge, J., Glöckner-Rist, A., \& Rist, F. (2013). Positive und negative Metakognitionen über Krankheitssorgen. Psychotherapeut, 58(6), 560-568.

Barsky, A. J., Ettner, S. L., Horsky, J., \& Bates, D. W. (2001). Resource utilization of patients with hypochondriacal health anxiety and somatization. Medical care, 39(7), 705-715.

Barsky, A.J., Wyshak, G., \& Klerman, G. L. (1986). Medical and psychiatric determinants of outpatient medical utilization. Medical Care, 24, 548-560.

Bennett, H., \& Wells, A. (2010). Metacognition, memory disorganization and rumination in posttraumatic stress symptoms. Journal of Anxiety Disorders, 24(3), 318-325.

Bouman, T.K., \& Meijer, K.J. (1999). A preliminary study of worry and metacognitions in hypochondriasis. Clinical Psychology and Psychotherapy, 6, 96-101.

Cartwright-Hatton, S., \& Wells, A. (1997). Beliefs about worry and intrusions: The Meta-Cognitions Questionnaire and its correlates. Journal of Anxiety Disorders, 11, 279-296.

Cook, S. A., Salmon, P., Dunn, G., \& Fisher, P. (2014). Measuring Metacognition in Cancer: Validation of the Metacognitions Questionnaire 30 (MCQ-30). PloS one, 9(9), e107302.

Comrey, A. L. \& Lee, H. B. (1992). A first course in factor analysis. Hillsdale, NJ: Erlbaum.

Costello, A. B., \& Osborne, J. W. (2005). Best practices in exploratory factor analysis: four recommendations for getting the most from your analysis. Practical Assessment Research and Evaluation, 10(7), 1-9.

Diamantopoulos, A. \& Siguaw, J.A. (2000) Introducing LISREL. London: Sage Publications.

Eysenck, H. J. (1990). Biological dimensions of personality. In L. A. Pervin (Ed.), Handbook 
of personality: Theory and research (pp. 244-276). New York: Guilford Press.

Eysenck, S. B. G., Eysenck, H. J., \& Barrett, P. (1985). A revised version of the psychoticism scale. Personality and Individual Differences, 6, 21-29.

Fabrigar, L. R., Wegener, D. T., MacCallum, R. C. \& Strahan, E. J. (1999). Evaluating the use of exploratory factor analysis in psychological research. Psychological Methods, 4, 272-299.

Fergus, T. A. (2013). Repetitive thought and health anxiety: Tests of specificity. Journal of Psychopathology and Behavioral Assessment, 35(3), 366-374.

Ferguson, E. (2009). A taxometric analysis of health anxiety. Psychological Medicine, 39, 277-285.

Field, A. (2013). Discovering statistics using SPSS, London: Sage.

Fink, P., Ewald, H., Jensen, J., Sørensen, L., Engberg, M., Holm, M., et al. (1999).Screening for somatization and hypochondriasis in primary care and neurological in-patients: a seven-item scale for hypochondriasis and somatization. Journal of Psychosomatic Research, 46, (3), $261-73$.

Fink, P., Ørnbøl, E., \& Christensen, K. S. (2010). The outcome of health anxiety in primary care. A two-year follow-up study on health care costs and self-rated health. PloS one, 5(3), e9873.

Gerdes, T.T., Noyes, R., Kathol, R.G., Phillips, B.M., Fisher, M., Morcuende, M., et al (1996). Physician recognition of hypochondriacal patients. General Hospital Psychiatry, 18(2), 10612.

Gershuny, B. S. \& Sher, K. J. (1998). The relation between personality and anxiety: findings from a 3-year prospective study. Journal of Abnormal Psychology, 107, 252-262. 
Greeven A., van Balkom, A. J., Visser, S., Merkelbach, J. W., vanRood, Y. R., van Dyck, R.,Van der Does, A. J., Zitman, G. F., \& Spinhoven, P. (2007). Cognitive behaviour therapy and paroxetine in the treatment of hypochondriasis: A randomized controlled trial. American Journal of Psychiatry, 164, 91-9.

Gwilliam, P., Wells, A. \& Cartwright-Hatton, S. (2004). Does meta-cognition or responsibility predict obsessive-compulsive symptoms: A test of the meta-cognitive model. Clinical Psychology \& Psychotherapy, 11, 137-144.

Hair, Jr., J. F., Black, W. C., Babin, B. J., Anderson, R. E., \& Tatham, R. L. (2006). Multivariate Data Analysis (6th ed.).

Upper Saddle River, NJ: Pearson Prentice Hall.

Henson, R. K., \& Roberts, J. K. (2006). Use of exploratory factor analysis in published research. Educational and Psychological Measurement, 66(3), 393-416.

Hiller, W., Leibbrand, R., Rief, W. Fichter, M.M. (2005). Differentiating hypochondriasis from panic disorder. Journal of Anxiety Disorders, 19, 29-49.

Hollifield, M. (2001) Hypochondriasis and personality disturbance. In V.Starcevic \& D.R. Lipsitt (Eds.), Hypochondriasis: Modern perspectives on an ancient malady (pp. 103-126). New York: Oxford University Press.

Horn, J. (1965).A rationale and test for the number of factors in factor analysis. Psychometrika, 30(2), 179-185.

Hu, L., \& Bentler, P. M. (1998). Fit indices in covariance structure modeling: Sensitivity to underparameterized model misspecification. Psychological Methods, 3, 424-453. 
Hu, L., \& Bentler, P.M. (1999). Cutoff criteria for fit indexes in covariance structure analysis: Conventional criteria versus new alternatives. Structural Equation Modeling, 6, 1-55.

Hutcheson,G. \& Sofroniou, N. (1999) The Multivariate Social Scientist. Sage:London

Kaur, A., Butow, P., \& Thewes, B. (2011). Do metacognitions predict attentional bias in health anxiety? Cognitive Therapy and Research, 35, 575-580.

Kendler, K.S., Kuhn, J.W \& Prescott, C.A. (2004): Childhood sexual abuse, stressful life events and risk for major depression in women. Psychological Medicine, 34, 1475-1482.

Khawaja, N. G. \& McMahon, J. (2011). The relationship of Meta-worry and Intolerance of uncertainty with pathological worry, anxiety and depression. Behaviour Change, 28, 165180.

Leibbrand, R., Hiller, W. \& Fichter, M.M. (2000). Hypochondriasis and somatization: two distinct aspects of somatoform disorders? Journal of Clinical Psychology, 56, 63-72.

Marcus, D. K., \& Church. S. E. (2003). Are dysfunctional beliefs about illness unique to hypochondriasis? Journal of Psychosomatic Research, 54, 543-547.

Marcus, D. K., Hughes, K. T, \& Arnau, R. C. (2008). Health anxiety, rumination, and negative affect: A mediational analysis. Journal of Psychosomatic Research. 64,495-501.

Matsunaga, M. (2010). How to factor-analyse your data right: Do’s dont's, and how-to's. International Journal of Psychological Research, 3(1), 97-110.

Miles, J., \& Shevlin, M. (1998). Effects of sample size, model specification and factor loadings on the GFI in confirmatory factor analysis. Personality and Individual Differences, 25, 85-90. 
Moses, L.J., \& Biard, J.A. (1999). Metacognition. In R.A. Wilson \& F.C. Keil (Eds.), The MIT encyclopedia of the cognitive sciences (pp. 533-535). Cambridge: MIT Press.

Myers, S. \& Wells, A. (2005). Obsessive-compulsive symptoms: the contribution of metacognitions and responsibility. Journal of Anxiety Disorders, 19, 806-817.

Nunnally, J. C., \& Bernstein, I. H. (1994). Psychometric theory (3rd ed.).New York: McGraw-Hill.

O'Connor, B. P. (2000). SPSS and SAS programs for determining the number of components using parallel analysis and Velicer's MAP test. Behavior Research Methods, Instruments, \& Computers, 32, 396-402.

Olatunji, B. O., Kauffman, B. Y., Meltzer, S., Davis, M. L., Smits, J. A. J., \& Powers, M.B. (2014). Cognitive-behavioral therapy for hypochondriasis/health anxiety: a meta-analysis of treatment outcome and moderators. Behaviour Research and Therapy, 58, 65-74.

Papageorgiou, C., \& Wells, A. (2009). A prospective test of the clinical metacognitive model of rumination and depression. International Journal of Cognitive Therapy, 2, 123-131.

Patil, V. H., Singh, S. R., Mishra, S. K., \& Donovan, D. T. (2008). Efficient theory development and factor retention criteria: Abandon the 'eigenvalue greater than one' criterion. Journal of Business Research, 61(2), 162-170.

Pett, M. A., Lackey, N. R., \& Sullivan, J. J. (2003). The use of factor analysis for instrument development in health care research. Thousand Oaks, CA: Sage.

Pilowsky, I. (1967) Dimension of hypochondriasis. British Journal of Psychiatry, 113, 89-93.

Rief, W., Hiller, W., \& Margraf, J. (1998). Cognitive aspects of hypochondriasis and the somatization syndrome. Journal of Abnormal Psychology, 107 (4), 587-595. 
Salkovskis, P. M., Rimes, K. A., Warwick, H. and Clark, D., (2002) The Health Anxiety Inventory: Development and validation of scales for the measurement of health anxiety and hypochondriasis. Psychological Medicine: A Journal of Research in Psychiatry and the Allied Sciences, 32 (5), 843-853.

Schumacker, R. E. \& Lomax, R. G. (1996). A Beginner's Guide to Structural Equation Modeling. Mahwah, New Jersey: Lawrence Erlbaum Associates.

Snook, S. C., \& Gorsuch, R. L. (1989). Component Analysis Versus Common Factor-Analysis - a Monte- Carlo Study. Psychological Bulletin, 106(1), 148-154.

Spada, M. M., Mohiyeddini, C. \& Wells, A. (2008). Measuring metacognitions associated with Emotional distress: factor structure and predictive validity of the Metacognitions Questionnaire 30. Personality and Individual Differences, 45, 238-242.

Speckens, A. E. M., Van Hemert, A. M., Bolk, J. H., Roojimans, H. G. M. \& Hengeveld, M. W. (1996). Unexplained physical symptoms: outcome, utilization of medical care and associated factors. Psychological Medicine, 26, 745-752.

Speckens, A.E.M. (2001). Assessment of hypochondriasis. In V.Starcevic \& D.R. Lipsitt (Eds.), Hypochondriasis: Modern perspectives on an ancient malady (pp. 61-88). New York: Oxford University Press.

Sunderland, M., Newby, J. M., \& Andrews, G. (2013). Health anxiety in Australia: prevalence, comorbidity, disability and service use. The British Journal of Psychiatry, 202(1), 56-61.

Stewart, S. H., \& Watt, M. C. (2000). Illness Attitudes Scale dimensions and their associations with anxiety related constructs in a non-clinical sample. Behavior Research and Therapy, 38, 8399. 
Tabachnick, B.G. and Fidell, L.S. (2007), Using Multivariate Statistics (5th ed.). New York: Allyn and Bacon.

Taylor, S., \& Asmundson, G. J. (2004). Treating health anxiety: A cognitive-behavioral approach. New York: Guilford Press.

Thompson, B. (2004). Exploratory and confirmatory factor analysis. Washington, DC: American Psychological Association.

Tyrer, P., Cooper, S., Crawford, M., Dupont, S., Green, J., Murphy, D., ... \& Tyrer, H. (2011). Prevalence of health anxiety problems in medical clinics. Journal of psychosomatic research, 71(6), 392-394.

Weck, F., Bleichhardt, G., \& Hiller, W. (2010). Screening for hypochondriasis with the Illness Attitude Scales. Journal of Personality Assessment, 92(3), 260-268.

Weck, F., Neng, J.M.B., Richtberg, S. \& Stangier, U. (2012). Dysfunctional beliefs about symptoms and illness in patients with hypochondriasis. Psychosomatics, 53, 148-54.

Wells, A. (2009). Metacognitive therapy for anxiety and depression. New York: Guilford Press

Wells, A. \& Carter, K. (1999). Preliminary tests of a cognitive model of Generalised Anxiety Disorder. Behaviour Research and Therapy, 37, 585-594.

Wells, A., \& Carter, K. (2001). Further tests of a cognitive model of generalized anxiety disorder: Metacognitions and worry in GAD, panic disorder, social phobia, depression, and nonpatients. Behaviour Therapy, 32, 85-102.

Wells, A. \& Cartwright Hatton, (2004). A short from of the metacognitions questionnaire: properties of the MCQ-30. Behaviour Research and Therapy, 42, 385-396. 
Wells, A., \& Matthews, G. (1994). Attention and emotion: A clinical perspective. Hove, England: Lawrence Erlbaum Associates.

Wells, A., \& Matthews, G. (1996). Modelling cognition in emotional disorder: The S-REF model. Behaviour Research and Therapy, 34, 881-888.

Widaman, K. F. (1993). Common Factor-Analysis Versus Principal Component Analysis Differential Bias in Representing Model Parameters. Multivariate Behavioral Research, 28(3), 263-311.

Worthington, R. L., \& Whittaker, T. A. (2006). Scale development research a content analysis and recommendations for best practices. The Counseling Psychologist, 34(6), 806-838.

Zhang, Y., Zhao, Y., Mao, S., Li, G., \& Yuan, Y. (2014). Investigation of health anxiety and its related factors in nursing students. Neuropsychiatric disease and treatment, 10, 1223.

Zwick, W.R. \& Velicer, W.F. (1986). Comparison of five rules for determining the number of components to retain. Psychological Bulletin, 99, 432-442. 
Table 1: Principle components analysis pattern matrix rotated to the promax criterion using principal components method.

\begin{tabular}{|c|c|c|c|}
\hline & \multicolumn{3}{|c|}{ Component } \\
\hline & 1 & 2 & 3 \\
\hline $\begin{array}{l}\text { 3. I will be punished for thinking I am in good health. } \\
\text { 20. Thinking positively about my health will tempt fate and I will become ill. } \\
\text { 13. Thinking the worse about symptoms will keep me safe. } \\
\text { 16. Worrying about my health will help me cope. } \\
\text { 15. If I think positively about physical symptoms I will be caught off guard. } \\
\text { 7. Worrying about illness is likely to make it happen. } \\
\text { 5. Thinking negatively can increase my chances of disease. } \\
\text { 14. Worrying about my health will damage my body. } \\
\text { 11.Some thoughts have the power to make me ill } \\
\text { 1. Thinking of illness could change my health. } \\
\text { 17. I have no control over thinking about my health. } \\
\text { 12. Dwelling on thoughts of illness is uncontrollable. } \\
\text { 19. Only if I have a diagnosis will I be able to stop worrying. } \\
\text { 2. I cannot have peace of mind so long as I have physical symptoms. }\end{array}$ & $\begin{array}{l}.840 \\
.798 \\
.743 \\
.728 \\
.624\end{array}$ & $\begin{array}{l}.812 \\
.792 \\
.687 \\
.670 \\
.643\end{array}$ & $\begin{array}{l} \\
\\
\\
\\
\\
.844 \\
.841 \\
.558 \\
.440\end{array}$ \\
\hline
\end{tabular}


Table 2. Exploratory factor analysis pattern matrix rotated to the promax criterion using principal axis factoring.

\begin{tabular}{|c|c|c|c|}
\hline \multirow[b]{2}{*}{ Items } & \multicolumn{3}{|c|}{ Factor } \\
\hline & 1 & 2 & 3 \\
\hline 5. Thinking negatively can increase my chances of disease & .868 & .053 & -.168 \\
\hline 7. Worrying about illness is likely to make it happen. & .805 & .050 & -.018 \\
\hline 14. Worrying about my health will damage my body. & .743 & -.060 & .039 \\
\hline 1. Thinking of illness could change my health. & .680 & -.053 & .068 \\
\hline 11. Some thoughts have the power to make me ill. & .656 & -.023 & .180 \\
\hline 3. I will be punished for thinking I am in good health. & .084 & .869 & -.206 \\
\hline 13. Thinking the worse about symptoms will keep me safe. & -.072 & .827 & -.024 \\
\hline 16. Worrying about my health will help me cope. & -.028 & .749 & .062 \\
\hline 15. If I think positively about physical symptoms I will be caught off guard. & .014 & .659 & .161 \\
\hline 20. Thinking positively about my health will tempt fate and I will become ill. & -.029 & .610 & .234 \\
\hline 12. Dwelling on thoughts of illness is uncontrollable. & -.041 & -.034 & .900 \\
\hline 17. I have no control over thinking about my health. & -.049 & -.064 & .889 \\
\hline 19. Only if I have a diagnosis will I be able to stop worrying. & .067 & .141 & .589 \\
\hline 2. I cannot have peace of mind so long as I have physical symptoms. & .187 & .068 & .502 \\
\hline
\end{tabular}


Table 3: Inter-correlations between metacognition about health, health anxiety, cognitions about body and health, and neuroticism.

\begin{tabular}{|c|c|c|c|c|c|c|}
\hline & 1 & 2 & 3 & 4. & 5. & 6. \\
\hline 1.MCQHAT & & & & & & \\
\hline 2.MCQHAC & $.825^{* *}$ & & . & & & \\
\hline 3.MCQHAP & $.851^{* *}$ & $.534^{* *}$ & & & & \\
\hline 4.MCQHAU & $.878^{* *}$ & $.562^{* *}$ & $.718^{* *}$ & & & \\
\hline 5.WI & $.693^{* *}$ & $.486^{* *}$ & $.596^{* *}$ & $.711^{* * *}$ & & \\
\hline 6.CABAH & $.540^{* *}$ & $.424^{* *}$ & $.450^{* *}$ & $.483^{* *}$ & $.447^{* *}$ & \\
\hline 7.EPQ & $.135^{*}$ & .035 & .121 & $.233^{* *}$ & $.372^{* *}$ & .086 \\
\hline
\end{tabular}

Note. MCQHAT= Metacognitions about Health Total; MCQHAC $=$ Beliefs that Thoughts can Cause Illness; MCQHAB = Beliefs about Biased Thinking; MCQHAU = Beliefs that Thoughts are Uncontrollable; WI = Whiteley Index; CABAH = Cognitions about Body and Health Questionnaire; EPQ = Eysenck Personality Questionnaire.

${ }^{* *}$ Correlation is significant at the .001 level (two-tailed). ${ }^{*}$ Correlation is significant at the .001 level (one-tailed). 
A Measure of Metacognitive Beliefs in Health Anxiety 28 